\title{
Enamel demineralisation as an iatrogenic effect of Orthodontic treatment: a clinical review
}

SADJ October 2018, Vol. 73 No. 9 p563 - p570

S Omar ${ }^{1}$, SM Dawjee ${ }^{2}$

\section{SUMMARY}

Small areas of demineralised enamel, commonly referred to as white spot lesions (WSLs), constitute an important clinical problem in Orthodontics following treatment with fixed appliances. They are the result of an imbalance between de- and remineralisation of enamel, caused by the interrelationship of several factors.

Clinicians and patients are usually so focussed on the alignment of teeth within the arches and the relationship of the jaws to each other, that the iatrogenic effects of demineralisation and WSLs are often overlooked.

While attempts should be, and are, made to prevent this clinical problem, it can pose a challenge to manage in high risk patients.

Benefit must supersede risk and it is thus of utmost importance that the clinician be aware of and educates the patient on means to prevent or to minimise and manage WSLs. This manuscript is intended to elucidate the presentation, aetiology and management of WSLs, in the hope of promoting more favourable clinical outcomes for both patient and practitioner.

\section{DEFINITION}

White spot lesions are the earliest clinical sign of dental caries. They can be defined as 'subsurface enamel porosities' caused by an imbalance between deand remineralisation.

Enamel translucency relates to the degree of mineralisation and initial demineralisation presents as 'milky-white opacities' on the smooth surfaces of teeth. ${ }^{1}$ Such lesions can develop within a period of four weeks - the time between one Orthodontic appointment and the next. ${ }^{2}$

Author affiliations:

1. Shazia Omar, $B C h D$ (UWC), PDD (UWC), Department of Orthodontics, Oral and Dental Hospital, University of Pretoria.

2. S.M. Dawjee, BChD, BChD Hons, MSc Odont, M Dent (Ortho), PGD Dip IRE, PhD, Department of Orthodontics, Oral and Dental Hospital, University of Pretoria.

Corresponding author: Shazia Omar

Department of Orthodontics, Oral and Dental Hospital,

University of Pretoria. Email address: dr.shaziaomar@gmail.com

\author{
ACRONYMS \\ CPP-ACFP: Casein Phosphopeptide-Amorphous \\ Calcium Fluoride Phosphate \\ CPP-ACP: Casein Phosphopeptide-Amorphous \\ Calcium Phosphate \\ Gl: $\quad$ Glass lonomer \\ RMGI: Resin Modified Glass lonomer \\ SBS: $\quad$ Shear Bond Strengths \\ WSL: White Spot Lesion
}

\section{INCIDENCE}

The presence of WSLs is significantly greater in Orthodontic patients and Orthodontically-treated arches, compared with non-Orthodontic patients and untreated arches in Orthodontic patients., 4 The overall incidence varies greatly between $2 \%$ and $96 \%,{ }^{5}$ with the prevalence of WSLs on at least one tooth found to be as high as $49.6 \%$ in Orthodontically-treated patients, compared with $24 \%$ in a control group of untreated patients. ${ }^{6}$

The large variation could be due to varying methods of assessment of demineralisation, whether developmental and other idiopathic enamel lesions or local environmental factors are taken into consideration, and whether any form of fluoride is being used during treatment. ${ }^{7}$

It has also been found that while the prevalence in male and female Orthodontic patients is the same, the severity of WSLs is greater in males, attributed to a lower standard of oral hygiene. ${ }^{8,9}$

\section{DISTRIBUTION}

The teeth most frequently affected are molars, maxillary lateral incisors, and mandibular canines and premolars. ${ }^{6,7}$ The surface most frequently affected is the vestibular surface, and the regions most frequently affected are the cervical and middle thirds of teeth. ${ }^{10}$ If tooth surfaces are divided into quadrants, larger lesions have been found to occur in the gingival quadrants, more specifically distogingival quadrants. With regard to the arches, maxillary anterior teeth are more severely affected than mandibular anterior teeth, with no significant difference between right and left sides of the respective arches. ${ }^{11}$ 


\section{AETIOLOGY}

\section{Microbial factors}

Streptococcus mutans have been found to be implicated in the initiation and progression of dental caries. These bacteria are able to synthesise extracellular glucans from dietary sucrose, which increases the cariogenicity of plaque. This causes an increase in plaque mass, promotes colonisation of Streptococcus mutans, and changes the diffusion properties of plaque matrix. ${ }^{12}$

Lactobacilli, which are found in large numbers in advanced carious lesions, are responsible for the further development of carious lesions but do not play a major role in the initiation of lesions. ${ }^{12} \mathrm{~A}$ fivefold increase in these bacteria has been found in patients undergoing active Orthodontic treatment. $^{13}$

Orthodontic appliances create retention sites that lead to an increased proliferation of Streptococcus mutans and Lactobacilli. The number of Orthodontic attachments, the length of treatment and the level of oral hygiene are factors influencing the problem. ${ }^{14}$

\section{Salivary factors}

Apart from the co-existence of the four factors needed for demineralisation to occur (namely bacterial plaque, fermentable carbohydrates, a susceptible tooth surface, and time), salivary parameters such as $\mathrm{pH}$, flow rate and buffering capacity are extremely important. They influence the degree of mineral loss after an acidic episode, the rate of progression of demineralisation, and the potential for repair. ${ }^{12}$

Typically, an increase in salivary flow rate promotes the physical cleaning action, increases its buffering capacity and antibacterial activity, and accelerates clearance of substrates. Salivary $\mathrm{pH}$ and buffering capacity both aid in neutralising the plaque acid. The $\mathrm{pH}$ generally follows the rate of secretion. Unstimulated saliva may have a $\mathrm{pH}$ less than 6 , which can rise to about 8 at high flow rates. A low $\mathrm{pH}$ favours aciduric bacterial colonies and a high $\mathrm{pH}$ maintains a high buffering capacity. ${ }^{15}$

\section{Environmental factors}

\section{Oral hygiene}

Both oral hygiene methods and the ability of the tongue to remove food particles from the mouth become more difficult when Orthodontic attachments are present. This leads to plaque accumulation and the breakdown of retained carbohydrates. ${ }^{12}$

\section{Diet}

The main dietary factor is frequency of carbohydrate consumption. When this increases, overlapping episodes of acid attack occur without any significant intervening recovery, which ultimately results in a net loss of minerals over time. ${ }^{12}$

\section{Fixed Orthodontic appliances}

The appliance itself creates stagnation areas, resulting in an increase in bacteria and plaque and promoting demineralisation. However, resting salivary flow rate (and thus salivary $\mathrm{pH}$ and buffering capacity) also increases during fixed appliance therapy. ${ }^{15,16}$ This effect counteracts the tendency for demineralisation and explains why there is little demineralisation in some patients with high plaque indices. Figure 1 shows the interrelationship between the various aetiological factors, which may result in either deor remineralisation.

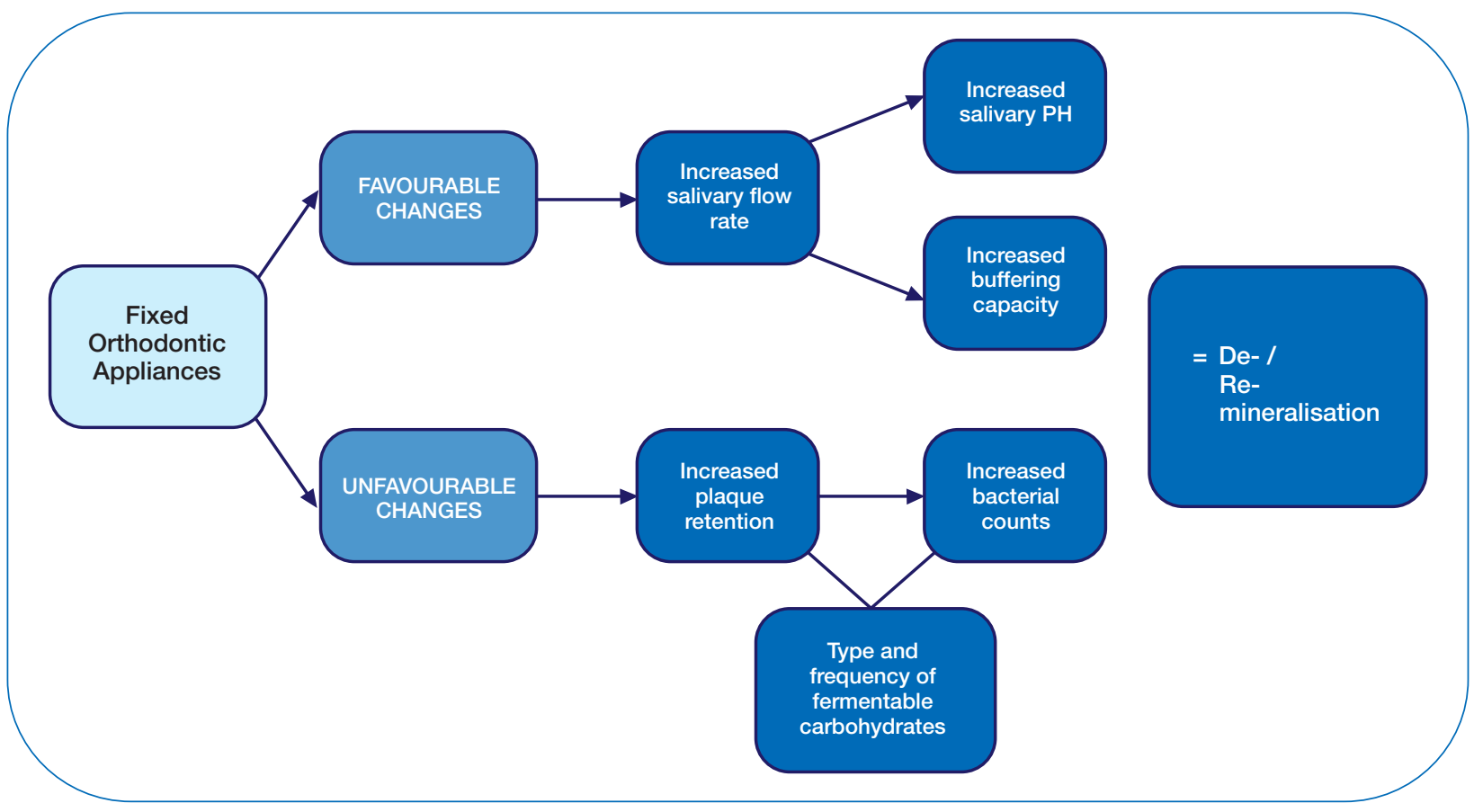

Figure 1. De- /remineralisation: inter-relationship between aetiological factors (Adapted from Chang et al, 1997.12). 


\section{CLASSIFICATION OF WHITE ENAMEL DISCOLOURATIONS}

Not all white enamel discolourations are of carious or demineralisation origin. Russell (1961) classified white tooth discolourations as:

1. Dental fluorosis

2. Non-fluoride opacities

3. White spot lesions

According to Russell's criteria, the following are features of each of the above discolourations...

\section{Dental fluorosis}

- White/yellowish lesions, ill-defined, blends with normal enamel, symmetric distribution.

\section{Non-fluoride opacities}

- Localised, well-differentiated from surrounding enamel, randomly distributed and often found in the centre of the tooth crown.

\section{White spot lesions}

- Seen in Orthodontic patients, under loose bands, around edges of bracket bases, and in areas that are difficult to clean. ${ }^{17}$

\section{METHODS OF EVALUATION}

Evaluation of demineralised white spot lesions is important to both clinicians and researchers. While various methods have been used to study the characteristics of these lesions, certain criteria are mandatory. Namely:

\section{Validity}

It should determine that the lesion was caused by mineral loss from enamel by acid demineralisation during Orthodontic treatment.

\section{Reproducibility}

A reading taken by an assessor at a specific time point should be very similar to a reading taken by that same assessor at a later time point, and readings of the same lesion taken by different assessors should be very similar.

\section{Ease of use}

It should easily be applied to clinical practice and be relatively inexpensive, and it should be able to assess two factors: whether demineralisation is present/absent, and measurement of the severity of the lesion. ${ }^{18}$

There are macroscopic and microscopic methods for the detection and measurement of demineralised white spot lesions.

\section{Macroscopic methods}

These methods rely on the change in optical properties of demineralised enamel.

Normal enamel is a low light-scattering material. Light photons entering it are backscattered, mostly by the underlying dentine. Demineralised enamel is a high light-scattering material. Light photons entering it trave a much shorter distance before being backscattered.
Most photons are now backscattered within the lesion itself rather than by the dentine, and the backscatter is also greater. This gives the clinical appearance of the white spot.

When such a lesion is dried and the water filling its porosities is replaced by air, the refractive index decreases further, resulting in an even whiter appearance of the lesion, ${ }^{18}$ as is often manifested by the chalky appearance of etched enamel.

Macroscopic methods include:

1. Clinical examination

2. Photographic examination

3. Optical non-fluorescent methods/light scattering

4. Optical fluorescent methods

Clinical examination is used to evaluate lesions before, during or after Orthodontic treatment. While this method is simple, inexpensive and clinically valid, the main disadvantage associated with its validity is the difficulty in distinguishing those lesions caused by demineralisation from lesions due to other causes.

Photographic examination, routinely used in research studies, provides a permanent record, has the potential to eliminate bias and is quite versatile. The main disadvantages associated with this method is over-estimation of the incidence of lesions due to the reflection of the flash, and standardisation with regards to tooth wetness and lighting.

Light scattering can be measured by means of the Optical Caries Monitor. This method uses a light source and measures the backscatter with a densitometer. It is a convenient, non-destructive and clinically applicable method, but can also prove to be technique sensitive.

Optical fluorescent methods use the property of fluorescence, which is a function of light absorption. With demineralised white spot lesions there is more backscatter, less absorption of light, and thus a lower intensity of fluorescence. For this reason, lesions appear as dark areas. Typical examples of this method are: fluorescent dye uptake, the use of ultraviolet light, laser (argon laser/quantitative laser fluorescence), Diagnodent, or light (quantitative light-induced fluorescence).

\section{Microscopic methods}

Microscopic methods typically use one of two models:

1. The Caries Model

2. The in situ Caries Model

The Caries Model involves the placement of bands or brackets on teeth destined for eventual extraction but allowed to remain in the oral cavity for a period. The extracted tooth is then evaluated using a destructive method, such as microhardness testing, microradiography or polarised light microscopy.

The in situ Caries Model is more sophisticated and involves sections of enamel instead of whole teeth. The enamel sections are placed in a removable appliance, which is worn by a volunteer, after which the sections are removed and evaluated. ${ }^{18}$ 


\section{PREVENTION DURING ORTHODONTIC TREATMENT}

\section{Caries risk assessment}

In order to implement effective preventative measures, it is important to identify those patients most at risk. This can be done using the Caries Risk Assessment tool. ${ }^{19}$ Factors noted during this assessment include:

1. Salivary flow rate

2. History of past enamel caries and caries incidence

3. Residence in fluoridated or non-fluoridated communities

4. Dietary patterns

5. Plaque scores

6. Microbial counts

(Streptococcus mutans and Lactobacillus)

\section{Patient education}

This forms an essential part of the Orthodontic treatment plan. The Orthodontist, together with the Dental Hygienist, is responsible for this education.

\section{Oral hygiene}

A good oral hygiene regimen is often considered the first step in lesion prevention. This involves proper toothbrushing, with a fluoridated dentrifice. Dentrifices usually contain fluoride compounds such as sodium fluoride, monofluorophosphate, stannous fluoride, amine fluoride, or a combination of these. The fluoride concentration may vary, but should not fall below $0.1 \%{ }^{20}$

The cariostatic potential of these dentrifices is a direct result of two occurrences: its ability to improve oral hygiene, and fluoride ions being incorporated into the enamel surface of the tooth to form a fluoroapatite crystal structure. This crystal structure has a lower solubility in the oral environment compared with the hydroxyapatite crystals of enamel, thus preventing dissolution and/or increasing remineralisation. ${ }^{21,22}$ However, in less compliant patients, regular use of a fluoridated dentifrice has been shown to be insufficient in prevention. ${ }^{23}$

\section{Fluoride}

Supplemental sources of fluoride are recommended for non-compliant patients. This fluoride needs to be present in saliva and plaque fluid, in order to have maximum effect on enamel.

Salivary and thus plaque-fluid fluoride has been found to be significantly higher following two weeks of daily use of a sodium fluoride rinse. ${ }^{24}$ It has also been shown that daily rinses containing $0.05 \%$ sodium fluoride (NaF) or weekly rinses containing $1.2 \%$ acidulated phosphate fluoride significantly decrease the incidence of lesions during Orthodontic treatment. ${ }^{23,25}$ For this reason, the daily use of a fluoride rinse has been recommended, as was suggested 30 years ago. ${ }^{26,27}$

In reality, however, Orthodontic patients who do not comply with proper oral hygiene procedures will most likely not comply with the daily use of fluoridated rinses. It has been shown that less than $15 \%$ of Orthodontic patients rinse daily as instructed. ${ }^{28}$ For these patients, topical fluoride, such as varnishes, solutions or gels, may be recommended.

The in-office application of high concentration fluoride varnish does not rely on patient compliance but may increase patient costs, increase chair time, and cause a temporary (yellowish) discolouration of teeth and gingival tissue. Nonetheless, both in vitro and in vivo studies have shown promising results. A particularly convincing in vivo study has shown that demineralised white spot lesions in Orthodontic patients may be reduced by up to $44.3 \%$ with twelve weekly applications of fluoride varnish. ${ }^{29}$

Resin sealants

Resin sealants may be applied to tooth surfaces, before or after bonding, to seal susceptible areas. Unlike early generation sealants, newer sealants have proven to be more wear resistant (as they are highly filled), with effective sealing abilities and often additional protection is offered by the incorporation of fluoride.

While it is true that there is a significant decrease in the concentration of fluoride released by fluoride-releasing sealants with time, the sealant is able to be recharged with fluoride ions (using an acidulated phosphate fluoride solution). ${ }^{30}$

In vitro studies have shown that the application of Pro-seal (Reliance $\AA$ ) results in a significant decrease in lesions, more than an unfilled resin sealant or fluoride varnish. ${ }^{31,32}$ In vitro studies on the product found a $98 \%$ reduction in demineralised white spot lesions, ${ }^{31}$ and a $92 \%$ reduction in lesion depth. ${ }^{32}$ While these findings are impressive, in vivo studies to support this are yet to be published.

\section{Adhesives}

Glass ionomer (GI) cements were first introduced as bonding adhesives due to their chemical bonding and sustained fluoride release. ${ }^{33}$ However, because of their low bond strengths, resin particles were added to create resin modified glass ionomer (RMGl) bonding adhesives. These adhesives have relatively higher bond strengths, while still releasing fluoride. Furthermore, in vivo studies have shown no significant differences with regards to bracket failure rates or shear bond strengths (SBS) between RMGI bonding adhesives and composite (resin) bonding adhesives. ${ }^{34,35}$ These RMGl adhesives may play a greater role in Orthodontics in the near future.

\section{Antimicrobials}

Attempts have also been made to incorporate antimicrobials into bonding adhesives or primers, without negatively affecting bond strengths. It has been shown that no significant decrease in shear bond strength occurs when chlorhexidine is added to bonding primers or applied once all bonding procedures are complete, but does occur when added as a separate varnish layer during bonding. ${ }^{36}$ It has also been shown that $2.5 \%$ cetylpyridinium chloride added to bonding adhesives does not significantly affect tensile bond strength, and leads to an inhibition of bacterial growth for 196 days. ${ }^{37}$ 
Interestingly, the combination of an antimicrobial selfetching primer and a fluoride-releasing adhesive has not been found to cause any significant reduction in shear bond strength, and has in fact been found to have a stronger shear bond strength than a conventional composite (resin) adhesive used with the usual acid-etch/ primer procedure. ${ }^{38}$

Antimicrobials may also be applied as varnishes. An in vivo study found that the combination of a fluoride and chlorhexidine varnish or a fluoride varnish alone, results in a $30 \%$ reduction of lesions.

The combination of varnishes does not lead to significantly less lesions than fluoride varnish alone, however, the combination of varnishes has been found to be specifically associated with half as many lesions on maxillary incisors. ${ }^{39}$ For this reason, it is important to consider the use of products combining fluoride and antimicrobials in patients who cannot maintain optimal oral hygiene.

\section{NATURAL REGRESSION}

Under normal circumstances, dental enamel is in equilibrium with the oral environment, and saliva contains all the elements required for hydroxyapatite crystal growth. In this natural state, demineralisation and remineralisation occur continuously.

Insertion of fixed Orthodontic appliances disturbs this natural balance, but with the removal of the appliance, a favourable balance between demineralisation and remineralization is again restored ${ }^{7}$ and as a result, lesions may undergo natural repair. Natural repair will occur in the presence of adequate amounts of salivary and plaque calcium, phosphate and fluoride ions, and provided other etiological factors are favourable. However, it has been shown that this natural repair is limited. ${ }^{40}$

\section{Time}

The most rapid reduction in lesion size without any treatment intervention has been found to occur during the first 12 weeks after fixed appliance removal, with little further reduction thereafter. Studies show that lesions reduce by one third after 12 weeks, and one half the size of the initial lesion after 26 weeks. ${ }^{41}$ Small lesions, however, have been found to show a rapid improvement six weeks after debonding, with little further improvement after six months. ${ }^{40}$

\section{Lesion size}

The severity of the lesion is another aspect which affects regression. A study in which patients were re-examined six years after debonding showed that while $75 \%$ of the small demineralized white spot lesions regressed during the six year time period, $25 \%$ of the most severe demineralised white spot lesions did not regress and remained visible on the tooth surfaces. ${ }^{42}$

It is important to note that clinical improvement in lesions is not just due to remineralisation, but also abrasion of enamel surfaces e.g. from toothbrushing. It has therefore been suggested that polishing or abrasion of dull and irregular enamel surfaces be done in order to expose more tightly packed enamel crystals which give a harder and glossier clinical appearance. ${ }^{42}$

\section{MANAGEMENT AFTER FIXED APPLIANCE REMOVAL}

While prevention of demineralised white spot lesions is ideal, in reality, these lesions may still occur. In general, management of demineralised white spot lesions should always commence with the most conservative approach. ${ }^{22}$ If such an approach fails to resolve the problem, a more aggressive approach should be adopted.

\section{Conservative/non-invasive approaches}

These approaches aim at remineralisation of lesions. The remineralisation process depends on various factors, such as the status of the lesion, lesion depth and the remineralising potential of various products. ${ }^{43,44}$ Many products on the market claim to promote remineralisation.

\section{Fluoride}

Topical fluoride is well-known and was used before the invention of other remineralising products. It is available in many forms e.g. toothpastes, gels, rinses or varnishes. After debonding, a saliva-mediated remineralisation usually takes place and the application of topical fluoride helps with this. ${ }^{45}$ The absorbed fluoride attracts available salivary calcium and phosphate ions and together the three are able to form a new crystalline structure, fluoroapaptite or $\mathrm{Ca}_{10}\left(\mathrm{PO}_{4}\right) \mathrm{F}_{2}$.

High concentrations of fluoride are important for prevention and seem to be beneficial in the management of lesions. However, the use of high concentrations on active lesions may cause surface hypermineralisation or plugging of diffusion pathways of enamel. The arrested lesion then remains the same size and often undergoes yellowish or dark brown staining. ${ }^{22}$ For this reason, many authorities warn against the use of high concentrations and advocate the use of low concentration fluorides. ${ }^{7,25,46,47}$

Despite the large amount of in vitro and in vivo studies testing lesion regression with the use of fluoride, $41,48,49$ there still seems to be confusion when it comes to how large a role additional fluoride (other than conventional use of a fluoridated toothpaste) plays in remineralisation and the management of lesions after Orthodontic treatment.

Casein phosphopeptide-amorphous calcium phosphate (CPP-ACP)

The use of CPP-ACP, a milk derivate, is a novel remineralisation approach. The CPP-ACP complex can be found in a wide range of tooth creams, pastes, gels and mousses. CPP stabilizes high concentrations of calcium and phosphate ions, as nanoclusters of ACP, in supersaturated solutions at the tooth surface, which can then act in the subsurface part of enamel lesions and effectively promote remineralisation. ${ }^{50}$

Most studies testing regression of lesions with the use of CPP-ACP containing products have shown that these 
products are, indeed, effective at remineralisation. ${ }^{51-54}$ However, one of these studies have shown that the remineralisation is not superior to 'natural regression' with the daily use of a fluoride toothpaste..$^{54}$

\section{Casein phosphopeptide-amorphous calcium fluoride phosphate (CPP-ACFP)}

CPP-ACFP can produce an outcome similar to that of CPP-ACP, but is further enhanced by the inclusion of fluoride. CPP-ACP and fluoride work synergistically and result in the formation of CPP-stabilised amorphous calcium fluoride phosphate at the tooth surface ${ }^{55}$ which results in increased concentrations of bioavailable calcium, phosphate and fluoride ions in the correct ratio to form fluoroapatite. ${ }^{56}$ The above concept has been used in many products such as CPP-ACFP-containing chewing gums and tooth creams.

Studies testing lesion regression with CPP-ACFP containing products have shown that these products (like CPP-ACP containing products) cause remineralisation throughout the body of the lesion instead of just at the surface, and that they may be more effective than CPP-ACP containing products or fluoride. ${ }^{56,57}$

Many reasons could exist as to why some of the above remineralisation studies present with contrasting results. Duration of studies differ greatly, with some being as short as 10 days and others running for periods up to six months. The period and frequency of application of product also varies in some instances. While it was easy to stipulate the size of lesions (small or deep) in in vitro studies, in vivo studies sometimes fail to classify lesions on the basis of their size. And lastly, methods of assessment also vary from study to study based on the specific parameters investigated e.g. change in surface area, depth or microhardness of lesions.

\section{Micro-invasive or minimally-invasive approaches \\ Resin infiltration}

This newer treatment modality uses a micro-invasive infiltration technique to halt progression of lesions that are too advanced for remineralisation.

It involves steps of prophylaxis, etching, rinsing, drying, application of Icon-Dry®, application of Icon ResinInfiltrant Smooth Surface $\AA$ and curing. This product, Icon Resin-Infiltrant Smooth Surface ${ }^{\circledR}$ (DMG), was specifically developed for infiltration on the smooth surfaces of teeth (particularly demineralised white spot lesions following Orthodontic treatment).

Resin infiltration improves the appearance of demineralised white spot lesions as a result of the similar refractive index of infiltrated and sound adjacent enamel. Both short and long-term studies have shown that this approach is able to effectively camouflage demineralised white spot lesions. ${ }^{58,59}$

\section{Microabrasion}

Microabrasion has been used in the past for the removal of superficial, non-carious enamel defects, but more recently, its use has been suggested for the management of stabilised or long-standing demineralised white spot lesions caused during Orthodontic treatment. ${ }^{7}$ Steps involved in this approach include prophylaxis, isolation, abrasion with a slurry of $18 \%$ hydrochloric acid mixed in a fine pumice, followed by application of a fluoride varnish. ${ }^{60,61}$

It has been shown that microabrasion leads to a significant reduction (83\%) of visible lesions and is thus effective in managing long-standing lesions. ${ }^{62}$

\section{Invasive approaches}

\section{Restorations and veneers}

The most aggressive approach is composite restorations or porcelain veneers. With composite restorations, and even more so with veneers, a large amount of tooth structure must be removed and so local anaesthetic is required. These treatment modalities also cost more, compared with other less invasive approaches. For these reasons, such an approach should be reserved for the most severe of lesions which cannot be managed by any other approach. ${ }^{22}$

\section{CONCLUSION}

Demineralised white spot lesions are an iatrogenic effect of Orthodontic treatment. Their prevalence in Orthodontic populations is particularly high, and since they affect teeth in the aesthetic zone, they prove to be a concern to both patient and clinician alike.

While prevention is ideal, high risk patients may still present with these lesions and their management becomes increasingly important. While there are many different treatment modalities to manage these lesions, prevention is optimal and should constitute the first line of defence. 


\section{References}

1. Summitt JB. Fundamentals of Operative Dentistry: A Contemporary Approach. 3rd ed. Chicago: Quintessence Pub.; 2006.

2. Øgaard B, Rølla G, Arends J. Orthodontic appliances and enamel demineralization: Part 1. Lesion development. American Journal of Orthodontics and Dentofacial Orthopedics 1988;94(1):68-73.

3. Wisth P, Nord A. Caries experience in Orthodontically treated individuals. The Angle Orthodontist 1977;47(1):59-64.

4. Willmot D, Brook A. The incidence of post-orthodontic demineralised enamel lesions in an orthodontic clinic. Journal of Dental Research 1999;78(5):1049-.

5. Mitchell L. Decalcification during orthodontic treatment with fixed appliances - An overview. British Journal of Orthodontics 1992;19(3):199.

6. Gorelick L, Geiger AM, Gwinnett AJ. Incidence of white spot formation after bonding and banding. American Journal of Orthodontics 1982;81(2):93-8.

7. Willmot D. White spot lesions after orthodontic treatment. Seminars in Orthodontics 2008;14(3):209-19.

8. Mizrahi E. Enamel demineralization following orthodontic treatment. American Journal of Orthodontics 1982;82(1):62-7.

9. Zachrisson BU, Zachrison S. Caries incidence and orthodontic treatment with fixed appliances. European Journal of Ora Sciences 1971;79(2):183-92

10. Mizrahi E. Surface distribution of enamel opacities following orthodontic treatment. American Journal of Orthodontics 1983;84(4):323-31.

11. Samawi S. Localisation and surface area measurement of post-orthodontic white lesions by computerized image analysis. University of Sheffield. 2005.

12. Chang $H$, Walsh $L$, Freer T. Enamel demineralization during orthodontic treatment. Aetiology and prevention. Australian Dental Journal 1997;42(5):322-7.

13. Sakamaki ST, Bahn AN. Effect of orthodontic banding on localized oral lactobacilli. Journal of Dental Research 1968;47(2):275-9.

14. Scheie A, Arneberg P, Krogstad O. Effect of orthodontic treatment on prevalence of Streptococcus mutans in plaque and saliva. European Journal of Oral Sciences 1984;92(3):211-7.

15. Andersson R, Arvidsson E, Crossner C, Holm A, Mansson B. The flow rate, $\mathrm{pH}$ and buffer effect of mixed saliva in children. Journal of the International Association of Dentistry for Children 1974;5(1):5.

16. Forsberg C-M, Oliveby A, Lagerlöf F. Salivary clearance of sugar before and after insertion of fixed orthodontic appliances. American Journal of Orthodontics and Dentofacial Orthopedics 1992;102(6):527-30.

17. Russell A. The differential diagnosis of fluoride and nonfluoride enamel opacities. Journal of Public Health Dentistry 1961;21(4):143-6.

18. Benson P. Evaluation of white spot lesions on teeth with orthodontic brackets. Seminars in Orthodontics 2008;14(3):200-8

19. Fejerskov O, Manji F. Risk assessment in dental caries. Risk assessment in dentistry Chapel Hill: University of North Carolina Dental Ecology 1990:215-7.

20. Øgaard B, Bishara S, Duschner H. Enamel effects during bonding-debonding and treatment with fixed appliances. Risk management in orthodontics: experts' guide to malpractice. Chicago: Quintessence 2004:19-46.

21. Øgaard B. White spot lesions during orthodontic treatment: mechanisms and fluoride preventive aspects. Seminars in Orthodontics 2008;14(3):183-93.

22. Bishara SE, Ostby AW. White spot lesions: formation, prevention, and treatment. Seminars in Orthodontics 2008;14(3):174-82.

23. O'Reilly M, Featherstone J. Demineralization and remineralization around orthodontic appliances: an in vivo study. American Journal of Orthodontics and Dentofacial Orthopedics 1987;92(1):33-40.
24. Duckworth R, Morgan S, Murray A. Fluoride in saliva and plaque following use of fluoride-containing mouthwashes. Journal of Dental Research 1987;66(12):1730-4.

25. Øgaard B, Rølla G, Arends J, Ten Cate J. Orthodontic appliances and enamel demineralization Part 2. Prevention and treatment of lesions. American Journal of Orthodontics and Dentofacial Orthopedics 1988;94(2):123-8.

26. Benson PE, Parkin N, Millett DT, Dyer F, Vine S, Shah A. Fluorides for the prevention of white spots on teeth during fixed brace treatment. The Cochrane Library 2004.

27. Zachrisson BU. Fluoride application procedures in orthodontic practice, current concepts. The Angle Orthodontist 1975; 45(1):72-81

28. Geiger AM, Gorelick L, Gwinnett AJ, Griswold PG. The effect of a fluoride program on white spot formation during orthodontic treatment. American Journal of Orthodontics and Dentofacial Orthopedics 1988;93(1):29-37.

29. Bowman SJ, Ramos AL. The effectiveness of a fluoride varnish in preventing the development of white spot lesions. World Journal of Orthodontics 2006;7:138-44.

30. Soliman MM, Bishara SE, Wefel J, Heilman J, Warren JJ. Fluoride release rate from an orthodontic sealant and its clinical implications. The Angle Orthodontist 2006;76(2):282-8.

31. Hu W, Featherstone JD. Prevention of enamel demineralization: an in-vitro study using light-cured filled sealant. American Journal of Orthodontics and Dentofacial Orthopedics 2005;128(5):592-600.

32. Buren JL, Staley RN, Wefel J, Qian F. Inhibition of enamel demineralization by an enamel sealant, Pro Seal: an in-vitro study. American Journal of Orthodontics and Dentofacial Orthopedics 2008;133(4):S88-S94.

33. Hallgren A, Oliveby A, Twetman S. Fluoride concentration in plaque adjacent to orthodontic appliances retained with glass Ionomer cement. Caries Research 1993;27(1):51-4.

34. Summers A, Kao E, Gilmore J, Gunel E, Ngan P. Comparison of bond strength between a conventional resin adhesive and a resin-modified glass ionomer adhesive: an in vitro and in vivo study. American Journal of Orthodontics and Dentofacial Orthopedics 2004;126(2):200-6.

35. Bishara SE, Ostby AW, Laffoon JF, Warren J. Shear bond strength comparison of two adhesive systems following thermocycling: a new self-etch primer and a resin-modified glass ionomer. The Angle Orthodontist 2007;77(2):337-41.

36. Bishara SE, Vonwald L, Zamtua J, Damon PL. Effects of various methods of chlorhexidine application on shear bond strength. American Journal of Orthodontics and Dentofacial Orthopedics 1998;114(2):150-3.

37. Al-Musallam TA, Evans CA, Drummond JL, Matasa C, Wu CD. Antimicrobial properties of an orthodontic adhesive combined with cetylpyridinium chloride. American Journal of Orthodontics and Dentofacial Orthopedics 2006;129(2):245-51.

38. Korbmacher HM, Huck L, Kahl-Nieke B. Fluoride-releasing adhesive and antimicrobial self-etching primer effects on shear bond strength of orthodontic brackets. The Angle Orthodontist 2006;76(5):845-50.

39. Øgaard B, Larsson E, Henriksson T, Birkhed D, Bishara SE. Effects of combined application of antimicrobial and fluoride varnishes in orthodontic patients. American Journal of Orthodontics and Dentofacial Orthopedics 2001;120(1):28-35.

40. van der Veen MH, Mattousch T, Boersma JG. Longitudinal development of caries lesions after orthodontic treatment evaluated by quantitative light-induced fluorescence. American Journal of Orthodontics and Dentofacial Orthopedics 2007;131(2):223-8.

41. Willmot D. White lesions after orthodontic treatment: does low fluoride make a difference? Journal of Orthodontics 2004;31(3):235-42.

42. Årtun J, Thylstrup A. A 3-year clinical and SEM study of surface changes of carious enamel lesions after inactivation. American Journal of Orthodontics and Dentofacial Orthopedics 1989:95(4):327-33. 
43. Guzmán-Armstrong S, Chalmers J, Warren JJ. White spot lesions: Prevention and treatment. American Journal of Orthodontics and Dentofacial Orthopedics 2010;138(6):690-6.

44. Sri-Aulawarat W, Nakornchai S, Thaweboon S,

Korsuwannawong S. Effect of tricalcium phosphate, casein phosphopeptide-amorphous calcium phosphate and sodium fluoride products on demineralization of artificial advanced enamel lesions. International Journal of Oral Research 2012;3:1-8.

45. Alexander SA, Ripa LW. Effects of self-applied topical fluoride preparations in orthodontic patients. The Angle Orthodontist 2000;70(6):424-30.

46. Linton JL. Quantitative measurements of remineralization of incipient caries. American Journal of Orthodontics and Dentofacial Orthopedics 1996;110(6):590-7.

47. Lagerweij M, Damen J, Stookey G. Remineralization of small enamel lesions by fluoride. Journal of Dental Research 1997;76:22-.

48. Du M, Cheng N, Tai B, Jiang H, Li J, Bian Z. Randomized controlled trial on fluoride varnish application for treatment of white spot lesion after fixed orthodontic treatment. Clinical Oral Investigations 2012;16(2):463-8.

49. Agarwal A, Pandey H, Pandey L, Choudhary G. Effect of fluoridated toothpaste on white spot lesions in postorthodontic patients. International Journal of Clinical Pediatric Dentistry 2013;6(2):85-8.

50. Reynolds E. Casein phosphopeptide-amorphous calcium phosphate: the scientific evidence. Advances in Dental Research 2009;21(1):25-9.

51. Andersson A, Sköld-Larsson K, Haligren A, Petersson LG, Twetman S. Effect of a dental cream containing amorphous calcium phosphate complexes on white spot lesion regression assessed by laser fluorescence. Oral Health \& Preventive Dentistry 2007;5(3)

52. Bailey D, Adams G, Tsao C, Hyslop A, Escobar K, Manton D, et al. Regression of post-orthodontic lesions by a remineralizing cream. Journal of Dental Research 2009;88(12):1148-53.

53. Hegde MN, Moany A. Remineralization of enamel subsurface lesions with casein phosphopeptide-amorphous calcium phosphate: A quantitative energy dispersive X-ray analysis using scanning electron microscopy: An in vitro study. Journal of Conservative Dentistry 2012;15(1):61-7.
54. Bröchner A, Christensen C, Kristensen B, Tranæus S, Karlsson L, Sonnesen L, et al. Treatment of post-orthodontic white spot lesions with casein phosphopeptide-stabilised amorphous calcium phosphate. Clinical Oral Investigations 2011;15(3):369-73.

55. Cross K, Huq N, Stanton D, Sum M, Reynolds E. NMR studies of a novel calcium, phosphate and fluoride delivery vehicle- $\alpha$ S1-casein (59-79) by stabilized amorphous calcium fluoride phosphate nanocomplexes. Biomaterials 2004;25(20):5061-9.

56. Reynolds E, Cai F, Cochrane N, Shen P, Walker G, Morgan M, et al. Fluoride and casein phosphopeptide-amorphous calcium phosphate. Journal of Dental Research 2008;87(4):344-8.

57. Cochrane N, Saranathan S, Cai F, Cross K, Reynolds E. Enamel subsurface lesion remineralisation with casein phosphopeptide stabilised solutions of calcium, phosphate and fluoride. Caries Research 2008;42(2):88-97.

58. Knösel M, Eckstein A, Helms H-J. Durability of esthetic improvement following Icon resin infiltration of multibracket-induced white spot lesions compared with no therapy over 6 months: a single-center, split-mouth, randomized clinical trial. American Journal of Orthodontics and Dentofacial Orthopedics 2013;144(1):86-96.

59. Eckstein A, Helms H-J, Knösel M. Camouflage effects following resin infiltration of postorthodontic white-spot lesions in vivo: one-year follow-up. The Angle Orthodontist 2015;85(3):374-80.

60. Welbury R, Carter N. The hydrochloric acid-pumice micro-abrasion technique in the treatment of post-orthodontic decalcification. British Journal of Orthodontics 1993;20(3):181-5.

61. Croll TP, Cavanaugh R. Enamel color modification by controlled hydrochloric acid-pumice abrasion. I. technique and examples. Quintessence International (Berlin, Germany: 1985) 1986;17(2):81-7.

62. Murphy TC, Willmot DR, Rodd HD. Management of postorthodontic demineralized white lesions with microabrasion: a quantitative assessment. American Journal of Orthodontics and Dentofacial Orthopedics 2007;131(1):27-33.

\section{Do the CPD questionnaire on page 588}

The Continuous Professional Development (CPD) section provides for twenty general questions and five ethics questions. The section provides members with a valuable source of CPD points whilst also achieving the objective of CPD, to assure continuing education. The importance of continuing professional development should not be underestimated, it is a career-long obligation for practicing professionals.

\section{Online CPD in 6 Easy Steps}

\footnotetext{
1 Go to the SADA website www.sada.co.za.

2 Log into the 'member only' section with your unique SADA username and password.

3 Select the CPD navigation tab.

4 Select the questionnaire that you wish to complete.

5 Enter your multiple choice answers. Please note that you have two attempts to obtain at least $70 \%$.

$6 \quad$ View and print your CPD certificate.
} 